\title{
Evolution of the Video Game Market
}

\author{
Analysis of the videogame target market throughout the years based on its marketing and \\ advertisement
}

\author{
Wildan Ali \\ Graphic Design and New Media Faculty \\ Bina Nusantara University \\ Jakarta, Indonesia
}

\begin{abstract}
The videogame industry had evolved since its initial appearance, and along with it, so has target market. This study attempts to analyse the trends throughout the years through observation of marketing materials such as printed and video advertisement commercials. The analysis is done by applying standard practice values employed in advertising communication on chosen samples of said commercial ads from each era of video game history.
\end{abstract}

Keywords-video games; gaming; gamers; consoles; commercial; advertisement

\section{INTRODUCTION.}

Since its introduction to homes in the early ' 70 s, video gaming had gone through many significant changes. Initially introduced as an electronic version of family gaming such as table top or board games, it eventually grew to become an entirely different entity. Like everything else which follows the growth of technology, the videogame industry continued to grow in potential, affecting content and use. This meant that while the first games were simple, it gradually became more and more complex. Complexity in gaming is not a necessarily a positive factor, as simplicity has later proved to attract a broader, more casual users.

In the years of the evolution of videogames, the industry has had to decide its target, mostly by capitalising on its technological advances and capabilities. The stigma of nonsocial, tech-oriented, young adult users had for a while had kept a broader market away from videogames. It wasn't until the era when technology facilitates more intuitive user interaction and input that the videogame industry came full circle and once again became embraced by the broader market.

This article is an attempt to analyse the trends throughout the history of videogame home console releases, basing the analysis on the available marketing samples. The scope of which will be home videogame consoles, not taking into account PC gaming. The analysis is also limited study in marketing and sales in North America with some influences from the Japanese marketing, due mainly to the availability of data and information sources. The analysis would be based on standard graphic design and advertising factors to determine the aims and goals of the marketing campaign. Sources would include video commercial archive available online as well as literature and studies made by experts in the field.

\section{HISTORICAL TIMELINE ANALYSIS.}

Videogames entered people's homes in 1972, with the Magnavox Odyssey. It was the first time an electronic device made specifically to play games were sold as a consumer product, since its technology-driven evolution which started in the 1950s. The Odyssey was marketed as a family entertainment system, as shown by the advertisement of the product, which featured family members from children playing with their parents to adults playing games with each other.

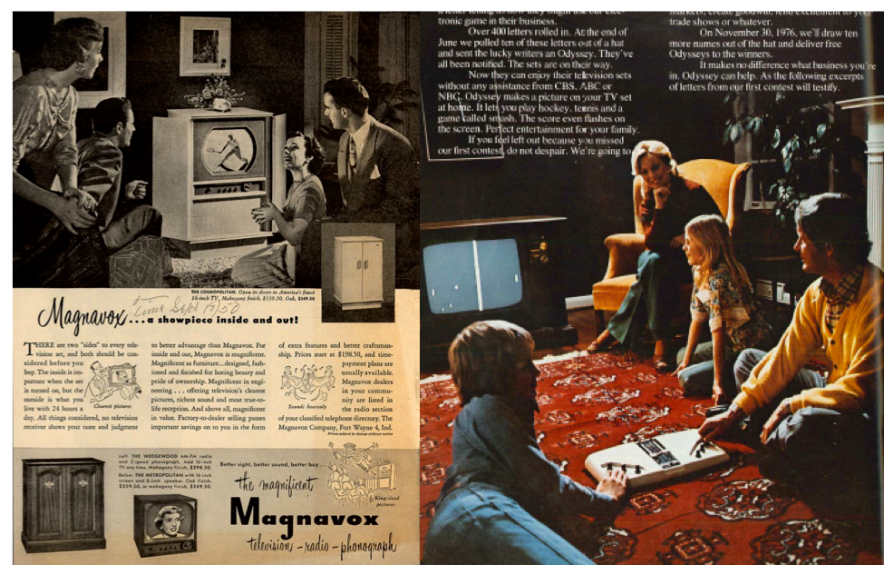

Fig. 1. Printed advertisement for the Magnavox featuring family settings.

When the Atari 2600 was released in 1977, there was already a slight shift in the marketing (and in turn, the target) towards a younger audience. Videogames, at least in the United States, is becoming the domain of younger users (children). 


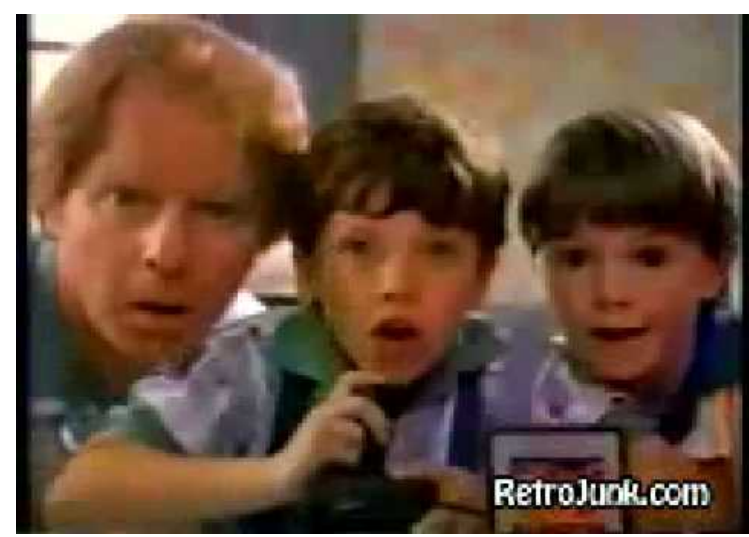

Fig. 2. Video advertisement for the Atari 2600.

However, the years since the 2600 's release saw a stagnated growth in videogame technology, and with the lack of innovation in concept and content to make up for it, the consumers rapidly got tired of videogames. And in 1983, as the market is saturated with Atari game clones, the very young videogames industry in North America crashed.

Japan, Nintendo in particular, had entered the videogames industry in 1971 when the company worked together with Magnavox to produce the optoelectronic guns (light guns) used on the Odyssey. Japan had not suffered the crash that had hit America, and their own videogames industry had flourished with the arcade gaming. In the same year the North American videogame industry crashed, Nintendo released the Famicom in Japan. The console would later be adapted to the American market in 1985 as the Nintendo Entertainment System (or the NES) and became a huge global hit, opening the way for Japan's dominance of the video gaming industry globally. A dominance which would last more than a decade.

Since the American market was still wary of videogames, viewing it as a trend which had died off, Nintendo of America needed to market the new console differently. The original Famicom had a top-inserted cartridge system similar to the Atari consoles, and in order to further it from that old image, the console was altered to feature front-inserted cartridge system resembling a VCR player.

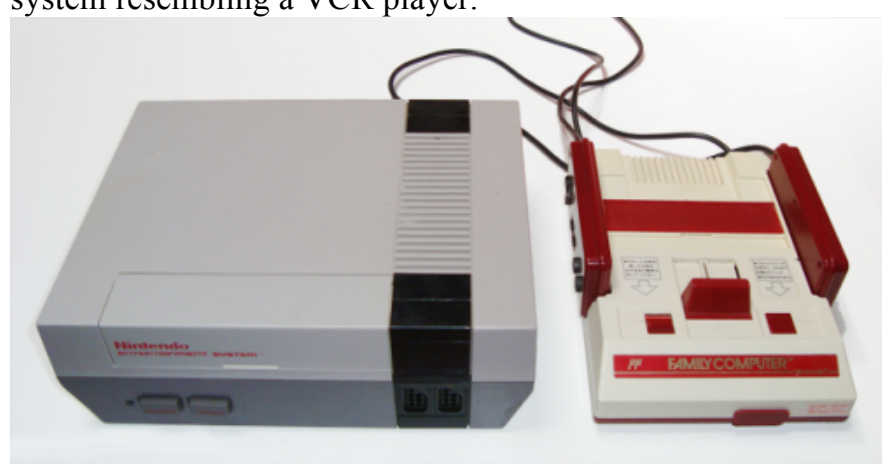

Fig. 3. The NES (left) and Famicom console designs.
The console was also called "Nintendo Entertainment System" as opposed to "Nintendo Videogame System". The NES was sold in bundles with the optional light gun and ROB (Robotic Operating Buddy). It was still marketed towards younger consumers, targeting the children and adolescents directly as opposed to the decision-makers (parents), as can be seen in the advertising, printed and video.

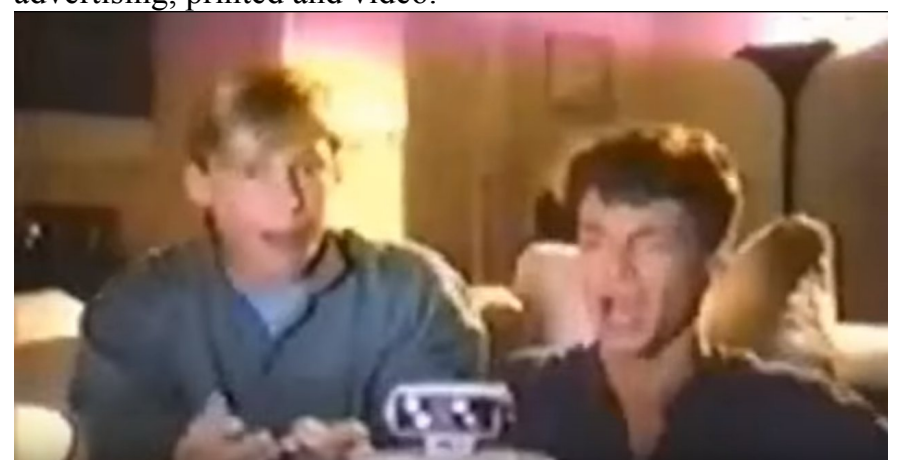

Fig. 4. Video advertisement for the NES.

Nintendo dominated the American 8 Bit console market as it did the Japanese market with its Famicom while Atari failed to re-establish a secure position in the market. Atari was initially approached by Nintendo to release their console under their brand but the cooperation did not happen, due to a number of reasons. And it was during this era, called the third generation of consoles era, that Nintendo and Sega became the dominant players in the industry. A trend which remained until Sony joined the industry a decade later with their release of the PlayStation console.

While the third generation still focused most of its marketing as an extension of the toy industry (as an effect of the aforementioned US market crash), the massive success of the NES as a videogame console in North America as well as Europe meant that the industry is aware that videogames in general had been accepted again by the market at large.

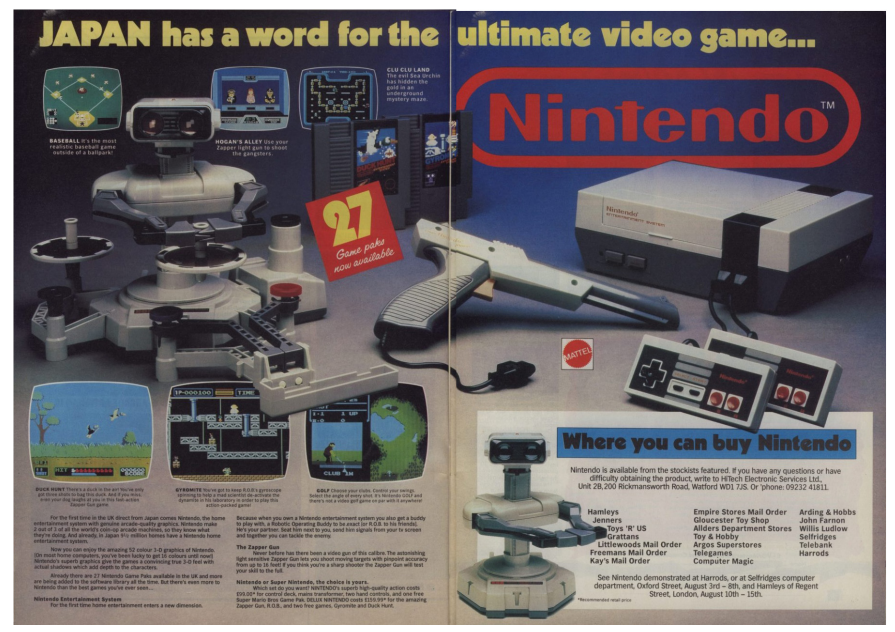

Fig. 5. Printed advertisement for the NES, featuring ROB.

Additionally, the superior technology allowed for more complex gameplays, creating diverse market segments for the 
differing genre of releases. This meant an equally more diverse strategy in marketing is required. It also shows that videogames is no longer just the simple form of mini games from the era of Atari, making it less prone to being stale. They are here to stay.

The fourth generation saw a more distinguished tone of marketing between the main players: Nintendo and Sega. As Nintendo prepared to release their follow up to the NES, the Super NES (called Super Famicom in Japan), Sega released their own 16 Bit console, the Genesis (called Mega Drive in Japan). A much more powerful machine than the ones before, the company can now use console power and capabilities as its selling points. The fourth generation was still dominated by Sega and Nintendo, but it also saw competition from companies such as Philips, Pioneer, and SNK, who produced their first home console, the Neo Geo. These other consoles failed to compete with the Super NES and Genesis.

Meanwhile, Nintendo and Sega entered into a head-to-head competition for the market. Each distinguishing themselves from the other by boasting such things as hardware capabilities of its console as well as the types of games they release.

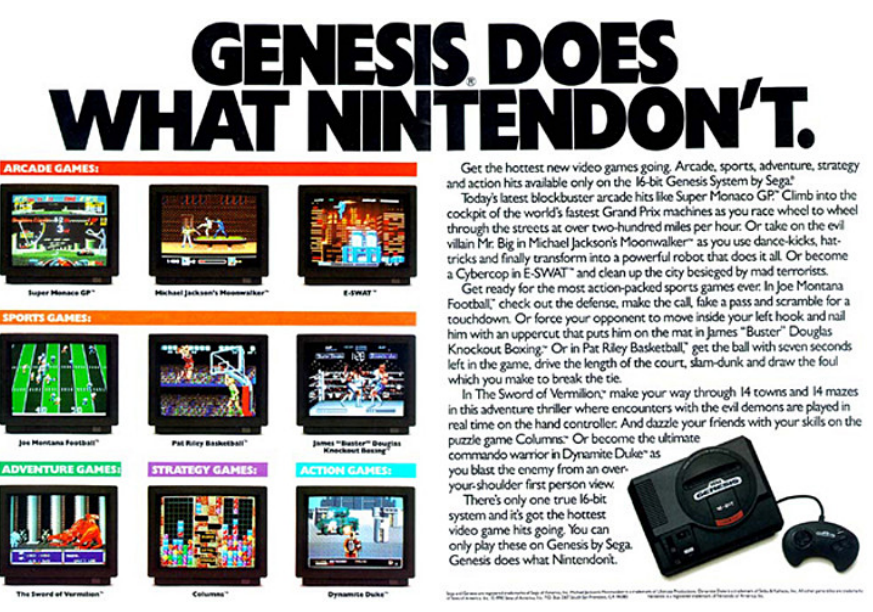

Fig. 6. Printed advertisement for the Genesis with their tagline attacking Nintendo while boasting their technical specs.

From the choice of words, visuals, editing and message, it is clear that both companies have steered away from targeting families or younger children, opting for young teens and adolescents. The marketing seems to be competing over which system is considered to be more "cool".

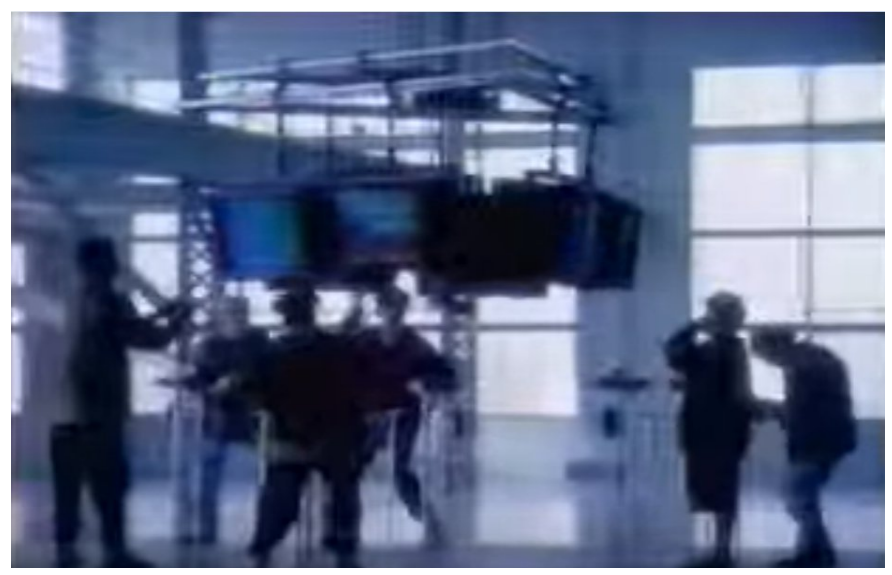

Fig. 7. Video advertisement for the Super NES, featuring "cool" teenagers.

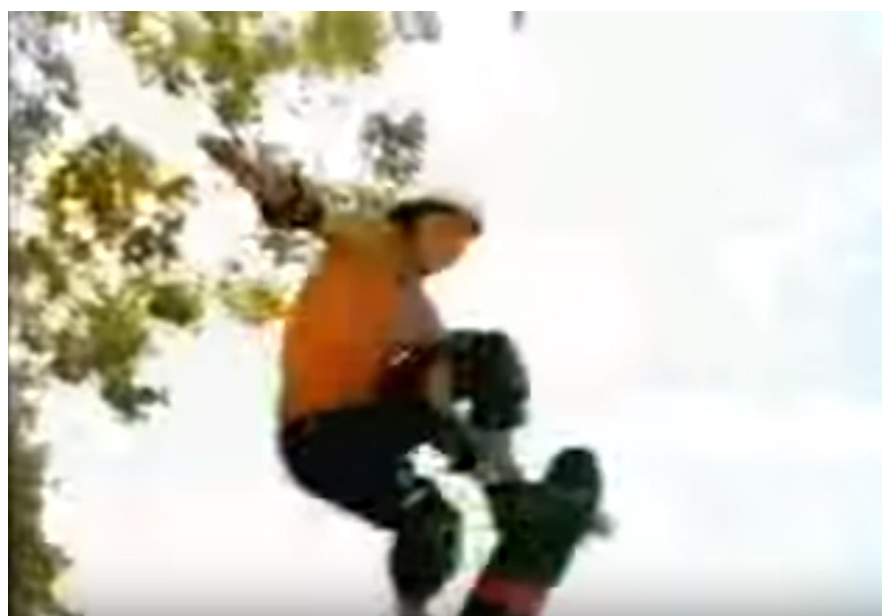

Fig. 8. Video advertisement for the Genesis, which, in addition to highlighting the "cool kids" imagery also directly compare the two systems.

This generation marks the debut of the Gameboy, Nintendo's handheld console, which became the second most popular handheld console of all time (the first place being Nintendo's 2004 handheld, the DS). Its sales obliterated all competition, cementing Nintendo's domination of the handheld gaming console (and therefore portable gaming) for over a decade, until when smartphone gaming became popular. Curiously, the Gameboy was not marketed towards the younger gamers, but to an older age group. The ads seem to put the Gameboy as an alternative for people who have busy lives, with work or other responsibilities, who need a short distraction and entertainment. Not unlike how mobile game apps are now being played. 


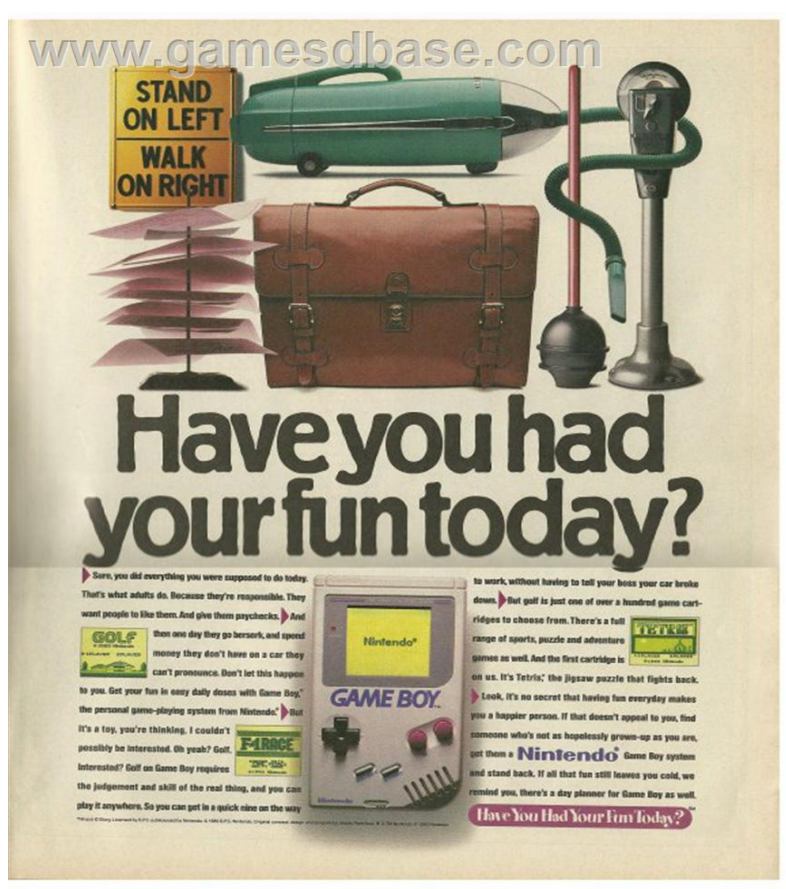

Fig. 9. Printed advertisement for the Gameboy, showing daily activity objects encountered by adults instead of children/teenagers.

The competition between Sega and Nintendo still followed in this period, with the Game Gear advertisement aggressively attacking not just the Nintendo Gameboy but also the consumers who bought them.

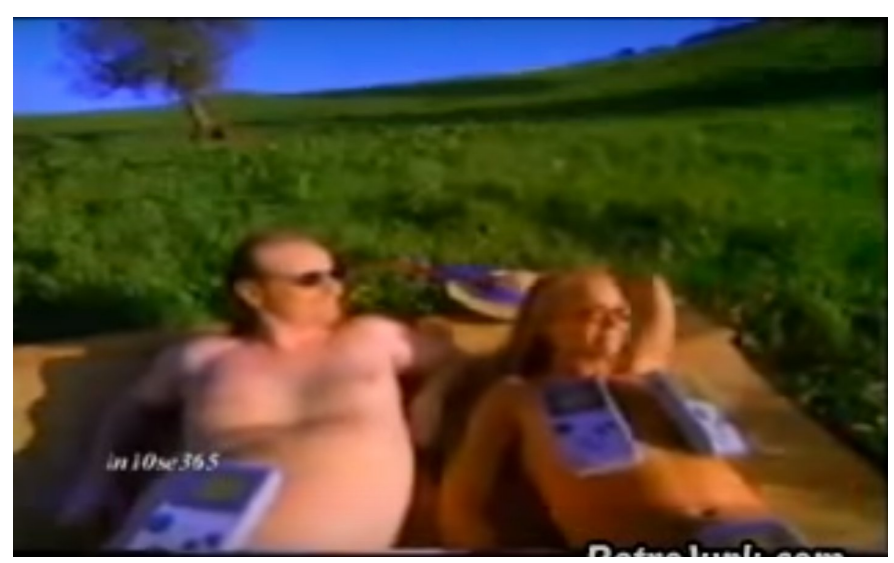

Fig. 10. Video advertisement for the Game Gear. Showing the Gameboy as useless objects and being used for ridiculous things. The presence of (covered) nudity clearly shows that the target is not younger people.

Like the Gameboy, Game Gear aimed towards an older generation of gamers. Their print ads show that they are certainly not aiming families. Since handheld games are physically limited to only one player (one small screen and one controller) without any additional hardware such as connector cables and, in the early days of handheld gaming, wireless connection, it is natural that the games are aimed to be played by single players, unlike the home consoles where gamers are encouraged to play together. With the very small exception of a few games, handheld titles are released and marketed as games which are to be enjoyed by a single player, as a form of "'me' time".

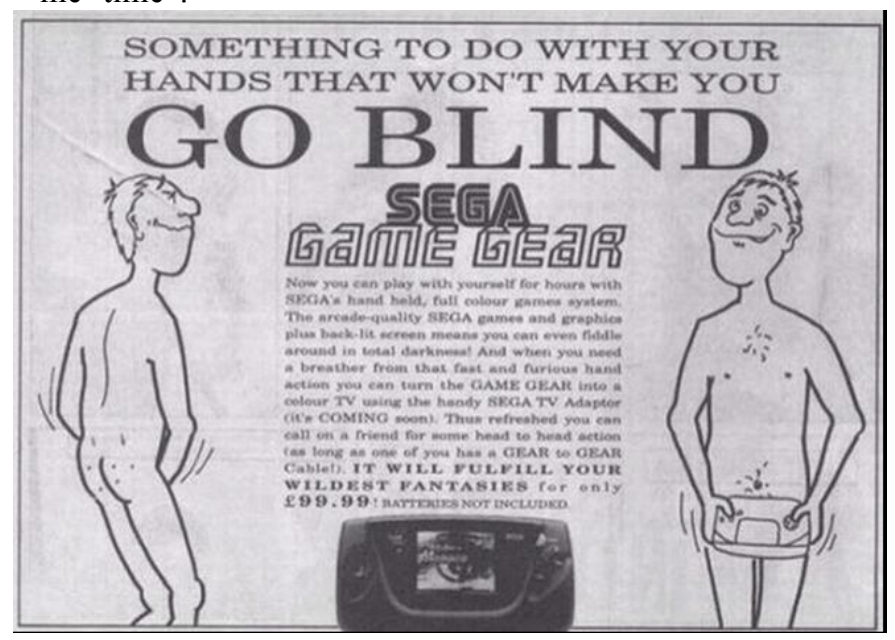

Fig. 11. Printed advertisement for the Game Gear, on men's magazines.

The 90s saw the growth of the video gaming technology, as computer hardware capabilities continued to increase. Everything from processors to graphic cards improved, giving game developers more options with which to create their games. The 90s was the time when Sony finally entered the console market, with the PlayStation console. When Sega created and released their arcade hit game Virtua Fighter, a fighting game utilising 3D polygon graphics, the team behind the creation of the original PlayStation console decided that their console would be focusing on 3D graphics rather than the then-traditional sprite-based graphics. Sony had initially sought a partnership with Nintendo to develop an add-on to the Super NES console, enabling it to play CD based games. But at the last moment, the deal was cancelled by Nintendo (who then partnered with Philips instead), and Sony decided to use the research results to develop their own console, the $32 \mathrm{Bit}$ PlayStation, marking the $5^{\text {th }}$ generation of videogame consoles. The PlayStation was released in Japan in 1994, and in the US in 1995. Sega also released their 32 Bit console, Saturn, in the same years. With revolutionary new graphics previously unavailable on the 16 Bit consoles, the sales of the PlayStation (now known as the PlayStation 1, or PS 1) skyrocketed in both Japan and the US. Nintendo never released a 32 Bit console, and released instead a 64 Bit console, the Nintendo 64 . However, due to the enormous success of the PlayStation in North America and Japan (and Saturn's success in Japan), the Nintendo 64 (or N64) had a difficult competition ahead of it in its release. Several other factors also proved to work against the N64. Arguably the biggest factor of all, was that Nintendo had insisted on keeping the game cartridge medium instead of switching to the much more economic and spacious CD format. The difference between which had made prominent game publishers move away from Nintendo and to Sony's PS 1 instead. Namely big name publishers such as Square, the publisher of such popular Role Playing Games (RPG games) as Final Fantasy and Chrono Trigger, who up until then had released exclusively for Nintendo. And also Capcom, publisher of game series such as Street Fighter and Rockman (Megaman 
in the US). Their departure meant a massive void is left in the N64's library, with mostly only first party titles like Mario and Zelda games making strong impressions in the market. With Saturn also failing to achieve the kind of success Sega had in the US with the Mega Drive and Atari's latest console barely getting any success at all, Sony's PS 1 had a real edge in leading the market in the generation it was introduced in. It went to become the second highest selling console of all time, behind the PS 2 a generation later.

Marketing on this generation focused mostly on technological advantages a console has. Real 3D polygon graphics became a selling point, with consoles boasting "realism" and dynamic visuals from games. The generation still aimed mostly at teenagers, adolescents, and young adults, with marketing ads containing imagery and phrases chosen to make the target market want to be part of something "cool". Humour was still used quite a lot, as is typical with the $80 \mathrm{~s}-90 \mathrm{~s}$ advertisements, but there are more attempts at experimental concepts, like the Saturn's TV ads.

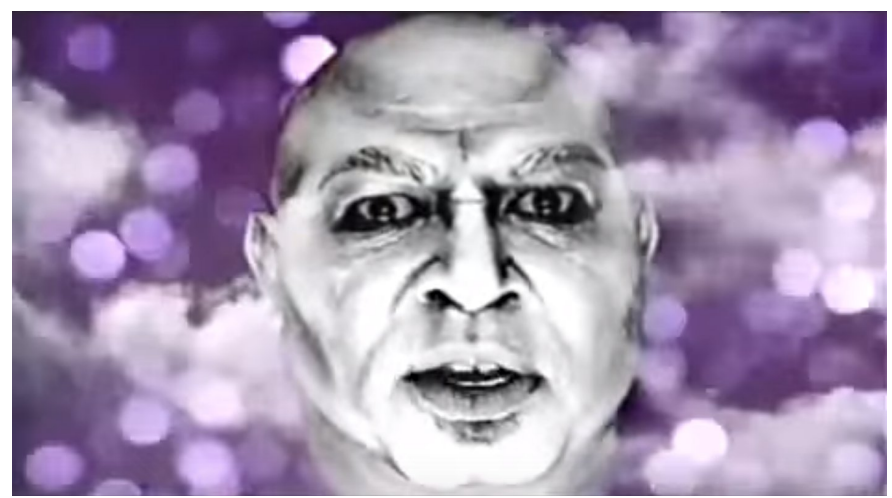

Fig. 12. Saturn's television commercial featured a bizarre talking head figure amidst showcasing its graphical capabilities.

The enormous sales of the PS 1 established ownership of a videogame console/gaming as the norm, something not even Nintendo, Atari or Sega had been able to do with their most popular product before this. This widespread market infiltration created future generations of video gamers, which help acceptance of the idea of someone being a gamer (or to a degree, a nerd) in popular culture. After the $5^{\text {th }}$ generation, playing videogames had arguably become as common as playing with toys or outside with friends. Essentially, before this, videogames had to be marketed as something that is cool, and that playing videogames would make you cool in effect, to counter the image that video games are for kids who are not active or worse, social. That there is a distinction between those who play and those who do not, and part of the message of the previous marketing was that it is not only "okay" to play games, but it actually makes you cooler. After the Playstation, marketing no longer needed to sell the image of playing a videogames: almost everyone is already a gamer. The message can then focus on other aspects of marketing the games, such as quality or type of experience of the games themselves, or distinctions between the games and the consoles.

Late 90s also marked the time when cell phones became more popularly used. As electronic technology grew, so did the specs and capabilities of even the standard mobile phone. They then started to feature other functions, one of which being the inclusion of mini games. Nokia began shipping their phones with "Snake", and other brands followed suit in adding games to their products. Despite the limitation of the screen size and lack of colour, this step in putting a game in a device which is carried at all times by adults also help push video gaming into the daily lives of non-gamers (later would also mean/include "casual gamers").

The sixth generation of game consoles started when Sega released what would be their final hardware, the Dreamcast. Shipped as early as 1998, it anticipated and took advantage of the advent of the popular use of the internet by including a builtin modem for online gameplay.

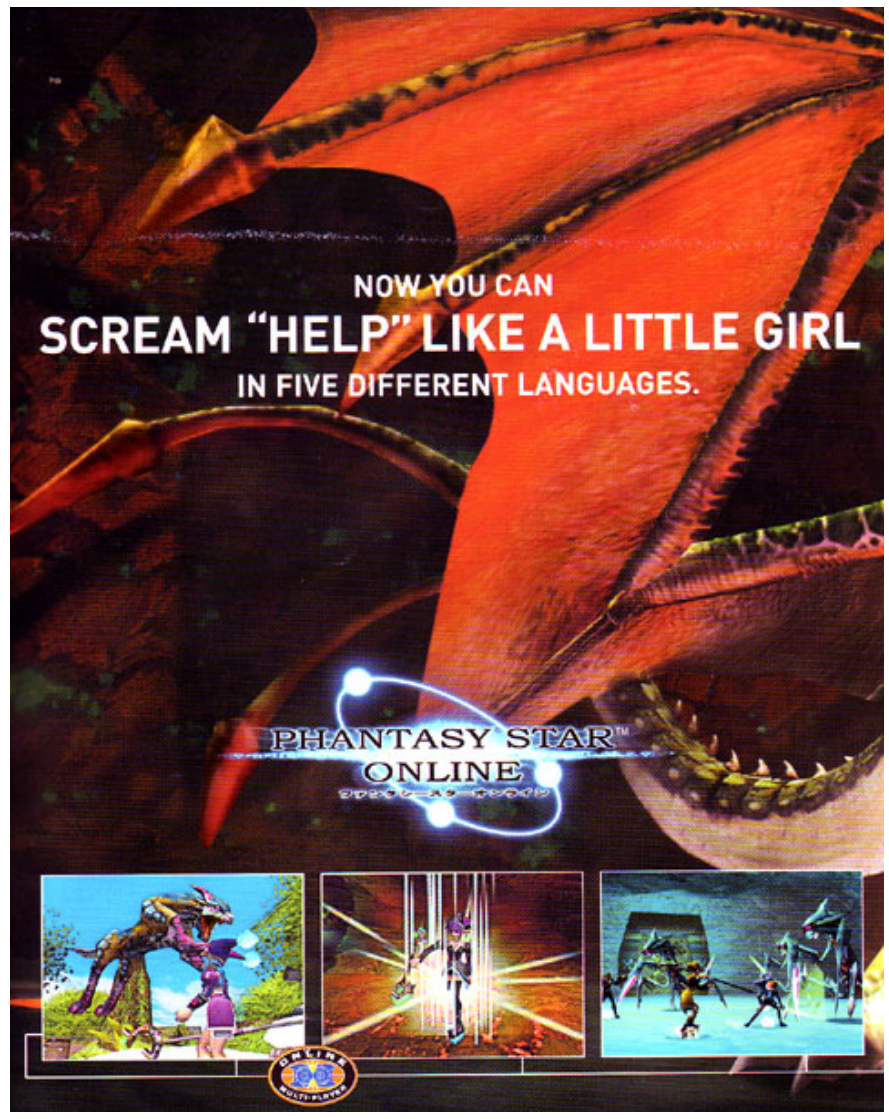

Fig. 13. Print ad for the Phantasy Star Online game, which took advantage of the SegaNet online functions and included an auto-translation function, so that players with different languages can play with each other.

Although the console would not end up being successful, it is still considered as a very influential release, particularly in retrospect. The Dreamcast featured accessories which were (and still are) uncommon, such as the microphone, the mouse and keyboard (for online play and interaction), the maracas, a 
fishing rod-like controller (ahead of a similar technology which would later be used on Nintendo's Wii), a digital camera which enabled exchange of photos online, and so on. These added functionality gave the Dreamcast a unique positioning: that it was not merely a console aimed at "hardcore gamers", but to anyone wanting to try out new ways of playing videogames. That meant also reaching casual gamers, had the sales been more successful. The many ways of interacting with the games or simply playing the games can be likened to how many game apps are now available for the mass market on gadgets such as the smartphone.

This generation also saw the release of the PlayStation 2 or PS 2, which what would be the highest selling console of all time. Sony released the console after the Dreamcast, and with it came a significant increase in hardware capabilities. It uses the DVD as its game medium, and also came with online support. Many popular game publishers released exclusives for the PS 2, boosting its popularity and sales. Square's Final Fantasy games as well as Konami's Metal Gear Solid games were PS 2 exclusives. Compared to the Dreamcast, the PS 2 is a more traditional gaming console, and with the exception of very few games such as Dance Dance Revolutions and the Guitar Hero series, the console was more known for its games for the "hardcore gamers" market. Although Sony did not initially establish its own online service like Sega's SegaNet, it still maintained an online gaming presence through third party servers such as the one provided by EA, which at that point released Sony exclusive titles. The PS 2's release was marketed as an "all-in-one" entertainment system, with its capability to play DVD movies making consumers consider it more than the other consoles which used alternative media such as the Dreamcast's GigaDisk and Nintendo GameCube's gamedisks. It meant that the console can be considered an excellent alternative to a DVD player, which were sold at roughly the same price. Sony's PS 2 success can also be attributed to a number of other things, such as the previous success of the PS 1 (which itself was a success due to many external factors, which then created a loyal market carrying over to the next gen), extensive third party game support, and backwards compatibility to play PS 1 games. None of the other consoles have this option.

The sixth generation also marked the debut of Microsoft in the videogame console market, with the Xbox being released late 2001. With Sega's departure from the console industry, the biggest players became Sony, Microsoft, and Nintendo. Microsoft complemented the Xbox with the launch of Xbox Live, the online fee-based service which enabled players to play online together.

In the handheld sector, Nintendo still dominated the market with its Gameboy Advance console (the GBA). Nokia briefly attempted to get into the handheld market with the release of the Nokia N-Gage, a phone/game console hybrid, but it did not achieve much success due to hardware design and high cost, especially when compared to the GBA with its library of games and select backwards compatibility. The release of the N-Gage did manage to attract the attention of game publishers, who noticed that mobile devices are now capable of enough processing power to be able to play traditional games. And while Nokia never released a follow up beyond the N-Gage QD upgrade, it eventually stayed in the gaming market by releasing its game library for its other phones. The mobile gaming market would later grow to extraordinary levels when smartphones became popular, and especially with the release of Apple's iPhone and other phones of that class.

This generation of videogames retained mostly its previous marketing strategy, with each console advertising its hardware and software capabilities to its core market (the hardcore gamers) with some non-traditional adverts every now and then such as the PS 2 commercial ad directed by famed surreal director David Lynch. The move to include some of these types of ads show a trust by the marketing towards the target market, that they understand the product's technical capabilities, and focusing instead on the image. Only a relatively mature target audience would be able to be addressed with this kind of message.

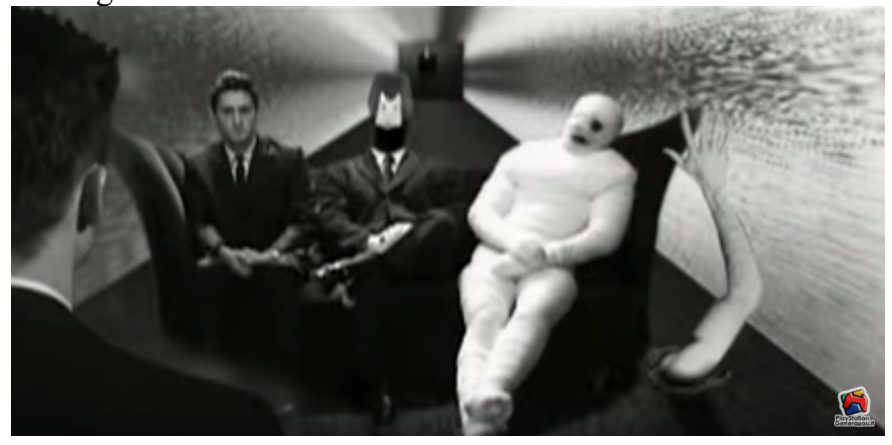

Fig. 14. The exceedingly bizarre commercial ad video by David Lynch for the PS 2.

Additionally, with the rise of online gaming and support for online gaming, games are also marketed as a means to interact with fellow gamers. Playing games together no longer meant actually being at the same place at the same time, and gamers who grew up with the older consoles had now become also reached a more independent phase in their lives. So while in the previous generation of gaming social video gaming meant arranging for a time and place to play together, potentially turning off older gamers from continuing, the option to play online whenever wherever meant that they did can still participate according to their own convenience. This had the effect of further establishing video games as part of the everyday person's lives. Entire generations who grew up playing games who kept playing games and will eventually parent new generations as parents who are wholly familiar with video games.

The next generation of consoles would include Sony's PlayStation 3, Microsoft's Xbox 360, and what would be Nintendo's most successful console of all time, the Wii. While the two big players (Microsoft and Sony) continued their race to release the most powerful consoles, Nintendo went into a drastically different direction with their new console. It was not 
powerful, did not feature high definition graphics, and featured a radically different game controller in the form of the Wii Remote and "Nunchuk". The Wii Remote (or the Wiimote) was shaped like a remote for electronic devices, but was built with an accelerometer and optical sensors, giving it motion sensing capabilities, enabling gesture recognition for object manipulation on screen. Nintendo had previously released the DS (Dual Screen), a handheld console which was the successor of the Gameboy lines, with two screens and stylus support as well as a built in microphone for interactive gaming purposes. The intuitive way players can interact with the games using the stylus, and the new potential unlocked with the then-unique way of playing games meant that players are opened up to a broader, more varied type of gaming. This added casual appeal to non-gamers, something that carried over to the Wii. The philosophy of the Wii console was player interaction. The console does not cater to hardcore gamers, but to casual gamers. Families and households, much like how the first generation of game consoles were marketed. This, plus the low price tag it came in, made it a huge hit. While the PlayStation 3 and Xbox 360 still boasted its specs and online gaming aspects in their marketing, the Wii opted to market the console as anyone's game system. The video ads featured a family with young children playing together, young people, and older men, all playing and enjoying casual gaming with simple, intuitive gameplay. The videogame was suddenly fun for everyone again, regardless of gender or age. The console also boasted its function to stay healthy with games such as Wii Sports and Wii Fit, challenging players to move and do exercise activities as part of their gaming.

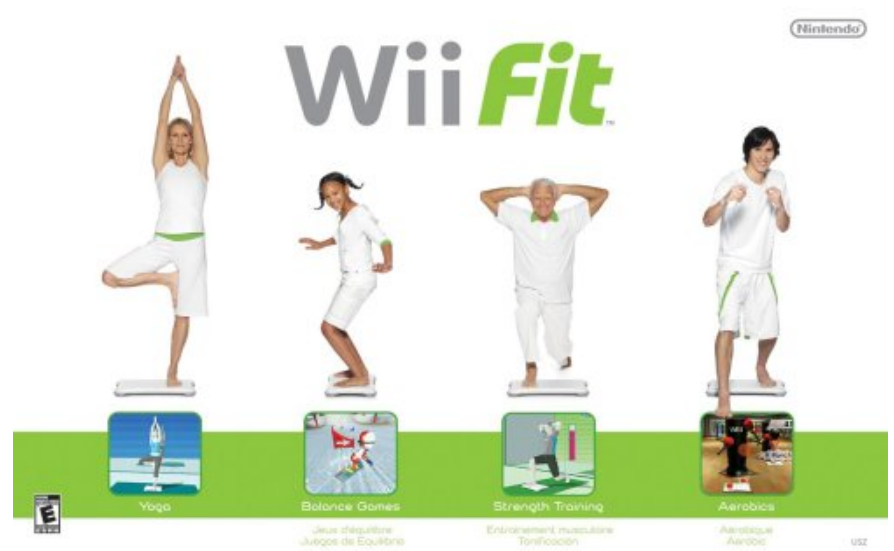

Fig. 15. The print advertisement of the Wii Fit, which showed people of different age, gender, and ethnicity, conveying the message that the game console is for everyone.

As more and more people are familiarised with the internet and made it a part of their lives, professionally and socially, technology also became more integrated in daily lives. Interconnectivity from social sites such as Facebook, Myspace or Friendster brought people online, and with it came casual networking games such as Farmville, Mob Wars, and so on. While the traditional, "hardcore" gamers follow on their gaming with powerful consoles such as the PlayStation and Xbox consoles, many others are drawn into videogames through these smaller, more causal games which promised to be short games with simpler rules. Publishers quickly saw this as a lucrative market, some opining that the casual gamers are the future of video gaming, and that casual gamers will outnumber traditional gamers.

When the iPhone was released in 2007, it was released as a combination of a handheld computer, a communication device, and an internet browser. It also featured Apple's App Store, which is an extension of their iTunes Music Store. The iPhone featured multi-touch screen for exceedingly intuitive user interaction, and gave way to very unique game apps with varied types of gameplay. The now-common intuitive interaction with games on the iPhone as well as other smartphones from other companies meant attracting even more casual gamers. People who are by then already very familiar with being online, with social gaming, and using/including personal gadgets in daily activities.

At the current moment, it is estimated that about $49 \%$ of adults in America play videogames, with only $10 \%$ describing themselves as a "gamer". This means that the remaining $39 \%$ consider themselves as casual gamers, almost twice the number of the traditional gamer. Videogames are now a part of many people's lives, and aside from major, high-profile, high-budget releases which are still common in franchise releases such as the Final Fantasy games, Metal Gear Solid, Grand Theft Auto and the such, most games no longer even require advertisement to market. Simple, social media based buzz may create enough interest to the games, which in most cases are low budget and low priced apps targeted at the casual gamers.

\section{CONCLUSION.}

Videogames had come a long way since its humble origins as a technological curiosity. What began as simple concept of using electronics to produce images and sounds which can be manipulated by a user, turning it into a game, had now become an inseparable aspect of daily modern life and an industry rivalling even Hollywood. It had taken years of evolution and gone through turbulent years, but with the support of the evergrowing technology, the integration of games in everyone's daily lives had become more and more seamless, turning practically everyone with access to a form of technology into a gamer, albeit a "casual" one.

The history of the marketing of videogames can be seen through the way they were advertised. And for the greater part of that history, it is more distinct and easily analysed. In the beginning sold as a novelty to families, to being marketed as a new form of toys for children and young adults, to being marketed as a lifestyle choice. As technology becomes more advanced and society becomes more and more accustomed to having technological products entwined in their daily lives, so has the evolution of videogames followed. Ranging from serving as minor recreational things to pass the time on short breaks to fully immersive, Hollywood style narrative entertainment experience taking hundreds of hours to complete. This broad spectrum of content has become too diverse to still 
be viewed as one simple entity called "the videogame" market. It has come to the point where each branching segment of the whole of the videogame industry aims at its own, individually broad range of target market.

Additionally, the current level of integration of videogames in the modern daily lives was helped largely by the fact that those who were the first adopters of video games (the children who grew up with videogames) have now grown to become adults and financially independent, free to make their own monetary spending decisions. Their love and usage of videogames in turn affect those around them, creating a culture which accepts videogame fandom whether they themselves are players. This fringe group outside of the main videogame players is also more prone to getting into casual gaming, supported by the availability of game apps on the gadgets they use.

Ultimately, it comes to the point where, outside of the major/blockbuster releases, many videogames no longer really needs to be advertised or marketed as intensely as it once did. In fact some games are no longer even marketed (or sold, as they are available for free), and have instead themselves become a host for advertisement, with companies and brands placing their ads within the games the way television and radio programmes run advertising to generate revenue. The once endangered little technological novelty has become a revenue juggernaut which not only have a full spectrum of target market, but is now a marketing tool on its own.

\section{REFERENCES}

[1] Emma Boyes. (2008, February 19). GDC '08: Are casual games the future? [Online]. Available: http://www.gamespot.com/articles/gdc-08are-casual-games-the-future/1100-6186207/

[2] Krista Lofgren (2016, February 8). 2016 Video Game Statistics \& Trends Who's Playing What \& Why [Online]. Available: http://www.bigfishgames.com/blog/2016-video-game-statistics-andtrends/

[3] Gamespot Staff. (2012, February 10). GameStop: Casual gamers spurring hardcore holiday sales [Online]. Available: http://www.gamespot.com/articles/gamestop-casual-gamers-spurringhardcore-holiday-sales/1100-6178563/

[4] DigThatBoxRETRO. (2014, May 4). Sega Saturn Infomercial - Sega Saturn Promotional Video - Sega Saturn [Online]. Available: https://www.youtube.com/watch?v=XjK0P_Qz0SA

[5] PlayStationGeneration.it. (2008, February 19). PlayStation 2 - The Third Place - David Lynch UK TV Advert [Online]. Available: https://www.youtube.com/watch?v=ge-gUEI1-24

[6] finalsignal. (2014, May 26). Sony PlayStation Launch Commercial - "U $\mathrm{R}$ Not e" retro game commercial 1995 [Online]. Available: https://www.youtube.com/watch?v=-IaJNizRmk8

[7] Zonkey Meat, (2014, April14). SEGA Game Gear Commercial 1990 [Online]. Available: https://www.youtube.com/watch?v=7NuBVcCGd6c

[8] DCIsAwesome. (2007, October 23). Sega Genesis Commercials [Online]. Available: https://www.youtube.com/watch? $=\mathrm{kEESjUQPhws}$

[9] SwozyGustafsson. (2010, June 20). 1991 Super Nintendo Commercial [Online]. Available: https://www.youtube.com/watch?v=BrI-A94aLfo

[10] gaastra. (2007, April). 2600: the fun is back! (1980) Video Games Commercial [Online] Available: http://www.retrojunk.com/commercial/show/3427/2600-the-fun-is-back 